\title{
Nostalgic Scent of Childhood Increases Creativity
}

\author{
Eirini Petratou, Nasia Paradisi, Odysseas Diamantis, Anastasios Stalikas \\ Department of Psychology, Panteion University of Social and Political Sciences, Athens, Greece \\ Email: eirini.petratou@gmail.com
}

How to cite this paper: Petratou, E., Paradisi, N., Diamantis, O., \& Stalikas, A. (2021). Nostalgic Scent of Childhood Increases Creativity. Psychology, 12, 205-222.

https://doi.org/10.4236/psych.2021.122013

Received: January 5, 2021

Accepted: February 7, 2021

Published: February 10, 2021

Copyright ( 2021 by author(s) and Scientific Research Publishing Inc. This work is licensed under the Creative Commons Attribution International License (CC BY 4.0).

http://creativecommons.org/licenses/by/4.0/ (c) (i) Open Access

\begin{abstract}
Creativity of an individual can be affected by emotions, memories, and associations with past experiences. This study examines the effects of nostalgia on divergent thinking component of creativity induced by olfactory cues and memory recall, more specifically what is the impact of olfactory nostalgia on creativity. The study participants were randomly assigned to olfactory, olfactory \& memory, memory, or control groups, and completed a creativity test. The study found that the combination of olfactory cues and nostalgia memory recollection triggering nostalgia boost divergent thinking and are correlated with positive emotions and inspiration. Our research findings on the impact of olfactory nostalgia contributes to the existing small body of experimental research on nostalgia effect on creativity and facilitates the understanding of the factors that can positively impact creativity and their psychological functions.
\end{abstract}

\section{Keywords}

Nostalgia, Childhood Scents, Memory, Creativity, Olfactory Nostalgia, Senses

"Your memory and your senses will be nourishment for your creativity" Arthur Rimbaud (2013). “A Season in Hell \& Illuminations”, Modern Library.

\section{Introduction}

Creativity could be considered as the formation of novel, original, and high-quality ideas that are also useful and adaptive (Runco, 2014; Runco \& Jaeger, 2012). Creativity research has focused on the investigation of cognitive mechanisms that are involved in the creative thinking process and the factors that can affect creativity (e.g., Bae \& Therriault, 2013; Arden, Chavez, Grazioplene, \& Jung, 2010). Cognitive underpinnings of creativity usually examined are specific think- 
ing processes such as associative (e.g., Benedek, Konen, \& Neubauer, 2012), divergent (e.g., Cho, Nijenhuis, Vianen, Kim, \& Lee, 2010; Nusbaum \& Silvia, 2011), and convergent (e.g., Brophy, 2000; Finke, Ward, \& Smith, 1992). In this study, we focus on divergent thinking and associative fluency and explore how they can be enhanced by olfactory stimulation.

Divergent thinking can be defined as the ideation process that involves generating a broad range of solutions or ideas to a given stimulus (Guilford, 1967; Runco, 2014). Creativity tests that assess divergent thinking present open-ended prompts (e.g., "Think of as many unusual uses as possible for a wooden pencil”, Guilford, 1967; Guilford, Merrifield, \& Wilson, 1958). A participant's goal in these tests is to generate as many ideas as possible. Responses are later scored according to a standardized procedure assessing creativity indicators, such as fluency and originality (Batey \& Furnham, 2006; Goff \& Torrance, 2002; Plucker \& Renzulli, 1999).

Associative processing is defined as the ability to fluently retrieve and combine remote associations, with respect to divergent thinking and intelligence (Benedek et al., 2012). It is involved in both divergent and convergent thinking (Bae \& Therriault, 2013; Eysenck, 1995; Martindale, 1999) and the main emphasis is given on the recombination of existing elements into novel products-the activation of mental networks made up of related (or associated) concepts and/or ideas (Bae \& Therriault, 2013). Four association tasks have been developed to measure associative processing: 1) associative fluency (i.e. ability to make freeassociations); 2) associative flexibility (i.e. ability to create an association-chain in which the word generated is associated only to the word that precedes it; 3 ) dissociative ability (i.e., ability to generate lists of unrelated words), and 4) associative combination (i.e., ability to generate word that is associated with a pair of unrelated words) (Benedek et al., 2012).

Studies have shown that divergent thinking and associative fluency can be improved by cognitive stimulation, mood, and meditation (Zmigrod, Colzato, \& Hommel, 2015). For example, research has shown that positive emotions determine better results regarding creative thinking and specifically: fluency, flexibility and originality (Vulpe \& Dafinoiu, 2011). Also, it was found that positive emotions compared to neutral states determine a higher creativity, but no significant differences were identified between positive and negative affect (Baas, De Dreu, \& Nijstad, 2008).

The present study examines nostalgia emotion and its effect on creativity (divergent thinking and associative fluency). Nostalgia is considered a bitter-sweet emotion and is constituted by happy feelings of positive memories of the past and negative feelings that derive mainly from strong longing for the past (Sedikides, Wildschut, Arndt, \& Routledge, 2006, 2008).

Nostalgia is strongly linked with olfactory experiences and memories (Reid, Green, Wildschut, \& Sedikides, 2015). The so-called Proust phenomenon or Proust memory is a folk wisdom evidence that smells are powerful autobiographical memory cues (Chu \& Downes, 2002, 2000). Research has revealed that 
not only do smells have this power to unlock memories, but they can also trigger older memories than memories cued by other sensory modalities such as words and pictures (Willander \& Larsson, 2006). For example, the study showed that most odor-cued memories were linked with the first decade of life ( $<10$ years), whereas memories associated with verbal and visual cues peaked in early adulthood (11 - 20 years) (Willander \& Larsson, 2006). Research exploring the strong bond between olfaction, memory and emotions has indicated that a key reason behind the unique ability of odors to vividly trigger the evocation of emotional experiences is the anatomic and functional relation between olfaction and emotion (Soudry, Lemogne, Malinvaud, Consoli, \& Bonfils, 2011). Olfactory cues activate the amygdala, while scent-cued memories are associated with greater limbic and temporal lobe activity, which is involved in positive memory processing (Royet, Zald, Versace, Costes, Lavenne, Koenig, \& Gervais, 2000). Research has shown that odors that evoke nostalgia have positive impact in self-esteem, self-continuity, optimism, social connectedness, and life meaning (Reid et al., 2015).

Research on the impact of nostalgia on creativity has shown that nostalgia state increases creativity since nostalgic experience evokes emotions and activates the cognitive process of recalling and reconstructing information in memory (Ye, Ngan, \& Hui, 2013). Also, creativity research revealed that nostalgic memories, defined as memories that trigger "a sentimental longing or wistful affection for the past" against both ordinary memories and happy memories as preparation for writing a short story, had a positive impact on creativity. The people who were asked to think nostalgically had more linguistic creativity in their stories, compared to other participants who were asked to think of ordinary or even happy memories (van Tilburg et al., 2015).

Most research in nostalgia has been done by inducing nostalgia through narrative tasks, song lyrics and music (Reid et al., 2015). In these cases, nostalgia has been induced through reflection of nostalgic memories (Routledge, Arndt, Sedikides, \& Wildschut, 2008), through reading the lyrics of a song that was previously identified as personally nostalgic (Cheung, Wildschut, Sedikides, Hepper, Arndt, \& Vingerhoets, 2013) or through listening to a variety of brief musical excerpts (Barrett, Grimm, Robins, Wildschut, Sedikides, \& Janata, 2010).

The current study examines nostalgia and its impact on creativity by inducing nostalgia through a nostalgic scent of childhood and reflection of nostalgic memories.

Findings of this study could shed light on ways of facilitating creativity of individuals and innovation in different domains.

\section{Present Study}

The purpose of the present study is to explore nostalgia and its impact on creativity, particularly flow and originality, in three different contexts: 1) Olfactory stimulation-without reflection of nostalgic memories; 2) Reflection of nostalgic 
memories-without olfactory stimulation and; 3) Combination of olfactory stimulation and reflection of nostalgic memories. Nostalgia is examined in the form of memory recall and smell of a childhood scent that evokes nostalgia. These two nostalgia induction forms are being used in isolation and in combination to understand which case(s) results in the most impactful creativity output.

The hypothesis is that the combination of olfactory nostalgia stimulation with reflection of nostalgic experiences will result in higher creativity. The research questions of this study are as follows:

1) Will the groups that will be triggered by olfactory nostalgia demonstrate higher creativity than the memory \& control groups? Research shows that scents are powerful triggers of nostalgia (Chelsea et al., 2015; Chrea et al., 2007) and that nostalgia increases creativity (van Tilburg et al., 2015; Ye, Ngan, \& Hui, 2013).

2) Will the groups that will be triggered by olfactory nostalgia report higher positive emotions and inspiration than the memory \& control groups? Research reveals that scents from childhood can have psychological implications (Chelsea et al., 2015; Chrea et al., 2007).

\section{Method}

\subsection{Participants, Material and Procedure}

Participants: We recruited undergraduate students from psychology within the age range of $18-25$ years $\left(\mathrm{N}=119\right.$; 91 women, 28 men; $\left.M_{\text {age }}=21\right)$; they had answered the Greek version of the Southampton Nostalgia Proneness (SNS) questionnaire (Petratou, Pezirkianidis, \& Stalikas, 2019) a month approximately prior to the experiment. The objective was to select the participants with moderate levels of nostalgia proneness (acceptable middle range of the 1 - 7 SNS scale: $\approx 4)$ to participate in the experiment. Then, students were randomly allocated to one of the four experiment groups (30 participants per group): 1) olfaction group (smell of the scent prior to the creativity exercises), 2) olfaction \& memory group (smell of the scent and memory activation prior to the creativity exercises), 3) control group (no scent, neither memory activation prior to the creativity exercises) and 4) memory group (memory activation prior to the exercises) (see also procedure per group).

Material: one scent that triggers nostalgia, bubblegum in the form of scented oil corresponding to childhood was selected from the sweets and treats category (Petratou, Paradisi, Diamantis, \& Stalikas, 2020). The scented oil was presented in glass test tube, masked so that the participants could not recognize the scent from any visual cue. The scented oil was obtained from a company (Nature's Garden Wholesale Candle and Soap Supplies) that sells and fragrances in $1 / 2$-ounce vials and has been used for studies that measure human response to olfactory stimuli (Reid et al., 2015).

Bubblegum was chosen as a nostalgic scent (Petratou, Paradisi, Diamantis, \& Stalikas, 2020) that has references to childhood-evokes nostalgia-without being affected by factors such as place of origin [e.g., nostalgia that could be caused 
by the smell of flowers or fruits could be related to the frequency of exposure to them (i.e. countryside vs city) or to specific periods of time (i.e. summer holidays vs winter) or seasons (i.e. Christmas)]. The scent was presented to the Olfactoy and the Olfactory \& memory groups (see also Procedure below).

Procedure: Participants were instructed two or three days prior to the test to avoid consuming food neither earlier nor later than 2 hours before the beginning of the day of the test since the olfactory perception could be affected by the degree of hunger (Ramaekers, Boesveldt, Lakemond, van Boekel, \& Luning, 2014); they were also instructed to not wear any perfume on the day of the test to avoid any bias or fatigue during when sniffing the test odors (the same guideline was applied for the test moderator). The above instructions were given to all groups, even the non-olfactory groups, to keep a common baseline of creativity. The test took place in a controlled lab setting with no stimuli (visual or olfactory) that could distract participants during the experimental process and impact the measurements; the room was also ventilated with fresh air in between sessions to maintain a neutral and unbiased setting for each session. Participants were placed at two meters between in each other to avoid any interaction or bias in the evaluation. Initially, each participant was asked to take a deep breath and relax by closing his/her eyes for 10 seconds. The goal was to establish a common, as much neutral as possible, emotional baseline/starting point for all participants before the beginning of the experimental measurements. Then, the test material was distributed to the participants and the measurements took place.

Participants were divided in four groups and followed the corresponding process as follows:

\section{1) Olfactory group}

Each participant sniffed the bubblegum scent, for approximately 3 - 4 seconds, and then directly filled in the nostalgia, inspiration and positive emotions questionnaires. Then he/she was asked to complete the Wallach-Kogan Creativity test (see also 3.2.5.).

\section{2) Olfactory \& memory group}

Each participant sniffed the bubblegum scent, for approximately 3 - 4 seconds and then was given the following instruction:

"Please think of a nostalgic event in your life. Specifically, try to think of an event from the past that causes you intense nostalgia. Bring this nostalgic experience to mind. Immerse yourself in this nostalgic experience. How does it make you fee?" (Hepper et al., 2012; Routledge et al., 2011; Wildschut et al., 2006). Then participants were asked to write down - for approximately five minutesall the feelings evoked by these nostalgic memories and then to fill in the nostalgia, inspiration and positive emotions questionnaires. Then he/she completed the Wallach-Kogan Creativity test (see also 3.2.5.).

\section{3) Memory group}

Participants were asked to think of a nostalgic event and immerse themselves in the nostalgic experience (as in the olfactory \& memory group): "Please think of a nostalgic event in your life. Specifically, try to think of an event from the 
past that causes you intense nostalgia. Bring this nostalgic experience to mind. Immerse yourself in this nostalgic experience. How does it make you fee?" (Hepper et al., 2012; Routledge et al., 2011; Wildschut et al., 2006). Then they were asked to write down all the feelings evoked by these nostalgic memories and then to fill in the nostalgia, inspiration and positive emotions questionnaires. Then he/she completed the Wallach-Kogan Creativity test (see also 3.2.5.).

\section{4) Control group}

Participants were asked to think of an ordinary event and immerse themselves in the past ordinary experience:

"Please bring to mind an ordinary event in your life. Specifically, try to think of a past event that is ordinary. Bring this ordinary experience to mind. Immerse yourself in the ordinary experience. How does it make you fee?" (Hepper et al., 2012; Routledge et al., 2011; Wildschut et al., 2006). Then they were asked to write down all the feelings evoked by these ordinary memories and then to fill in the nostalgia, inspiration and positive emotions questionnaires. Then he/she completed the Wallach-Kogan Creativity test (see also 3.2.5.).

\subsection{Measures}

\subsubsection{Southampton Nostalgia Scale (SNS)—Translated in Greek}

The SNS (Cheung, Sedikides \& Wildschut, 2017) gives participants a definition of "nostalgia" as provided by the Oxford Dictionary-a sentimental longing for the past-and then asks them to rate nostalgia proneness by filling seven items in total; four items measure frequency of nostalgic engagement ("how often do you experience nostalgia, 'generally speaking, how often do you bring to mind nostalgic experiences', specifically, how often do you bring to mind nostalgic experiences"; 1 = very rarely, 7 = very frequently) and three items assessing the importance assigned to nostalgic engagement ("how valuable is nostalgia for you", "how important is it for you to bring to mind nostalgic experiences?", "how significant is for you to feel nostalgic", "how prone are you to feeling nostalgic"; $1=$ not at all, 7 = very much) (Cheung, Sedikides \& Wildschut, 2017). For the test we used the Greek version of the SNS scale (Petratou et al., 2019).

\subsubsection{Nostalgia Assessment Questionnaire}

The questionnaire assessed whether each participant was feeling nostalgia on a 6-point scale (i.e., "Right now, I am feeling quite nostalgic", "Right now, I am having nostalgic feelings", "I feel nostalgic at the moment"). The three questions were calculated after the end of the measurements to form a single indicator of nostalgia (Hepper et al., 2012; Routledge et al., 2011; Wildschut et al., 2006).

\subsubsection{Inspiration Questionnaire}

Measurement of inspiration intensity (frequency was not assessed) per individual on a 7-point scale (i.e., "I experience inspiration", "Something I encounter, or experience inspires me", "I am inspired to do something", "I feel inspired"). The four questions were calculated after the end of the measurements to form a sin- 
gle indicator of inspiration (Thrash \& Elliot, 2003).

\subsubsection{Positive Emotions Questionnaire}

Questionnaire that measures on a 6-point scale the degree of positive affect (van Tilburg, Sedikides \& Wildschut, 2015). It included questions about the degree to which each individual felt positive (i.e., "Right now, I am feeling quite positive", "Right now, I am having positive feelings", "I feel positive at the moment"). The three questions were calculated after the end of the measurements to form a single indicator of positive emotions (van Tilburg et al., 2015).

\subsubsection{Wallach-Kogan Creativity Test (WKCT)}

Wallach-Kogan Creativity test consists of self-administrated exercises that are based on the associative perception of creativity which is strongly related to the recall of past experiences (Wallach \& Kogan, 1965a, 1965b). Three minutes are given for each exercise and the scoring of each exercise per participant is done by calculating the number of answers for each exercise and then adding the scores of each exercise to create a fluency index. Also, originality can be assessed by assigning one point for each unique response that appears only once in the total sample. The number of unique responses per group is summed to create an originality score for the corresponding group (Snyder, Mitchell, Bossomaier, \& Pallier, 2004).

The test is consisted of the following verbal and schematic exercises:

1) Cases (Verbal exercise)—creating possible cases of a concept (i.e., wheel movement) "Record anything that moves on a wheel".

2) Alternative uses (Verbal exercise) — thinking about possible uses of an object "Record different ways in which you could use a paper clip".

3) Similarities (Verbal exercise)—recording possible similarities between two objects "Record similarities between a cat and a mouse".

4) Pattern Interpretation (Schematic Exercise)-producing as many interpretations of a particular pattern as possible in an image; the following task was requested: "Record as many interpretations as possible for the illustrated pattern" (see Figure 1).

5) Line Interpretation (Schematic Exercise)-producing as many interpretations of the line as shown in the painting; the following task was requested: "Record as many interpretations as possible for the image below" (see Figure 2).

Wallach-Kogan Creativity test has been used in several studies investigating creativity and its linkage to psychological functions and intelligence (Şahin \& Lee, 2016; Silvia, 2008; Griffith \& Clark, 1981; Kazelskis, Jenkins, Lingle, \& Kazekskis, 1972; Cropley \& Maslany, 1969).

\section{Results}

The statistical analysis was carried out with the use of SPSS Vol.25.

Reliability analysis. Cronbach's Alpha-coefficient of reliability-was calculated to explore internal consistency of the scales that were used to measure how 


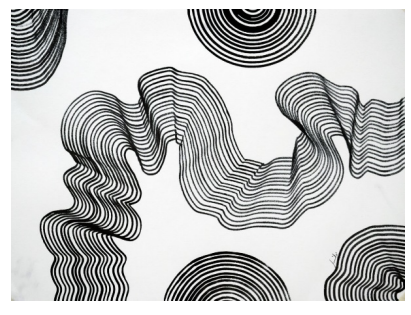

Figure 1. Pattern interpretation.

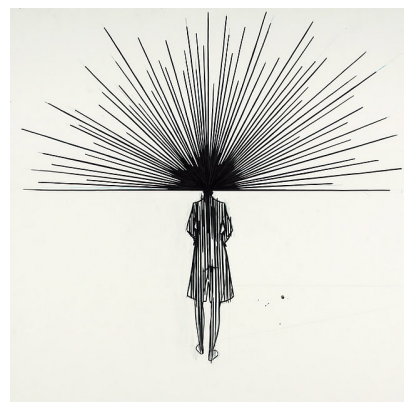

Figure 2. Line interpretation.

closely related the set of items per dimension they are as a group (Cohen, Cohen, West, \& Aiken, 2002).

Normality testing. Shapiro-Wilk test was used to test if the scores in the sample are normally distributed. The test is based on the correlation between the data and the corresponding normal scores and is recommended by researchers as the best choice for testing the normality of data (Thode, 2002).

Kruskal-Wallis test (or one-way ANOVA on ranks). To test if there are significant differences across the scents used for the study we used Kruskal-Wallis test, a non-parametric method. It is used for comparing two or more independent samples of equal or different sample sizes. The parametric equivalent of the Kruskal-Wallis test is the one-way analysis of variance (ANOVA). A significant Kruskal-Wallis test indicates that at least one sample stochastically dominates one other sample. For analyzing the specific sample pairs for stochastic dominance, Dunn's test, with Bonferroni correction, was used (Corder \& Foreman, 2009).

Correlation analysis. Correlation analysis was conducted to explore relationship-correlation coefficients $(\mathrm{r})$ - between the scent-level measures. Strong positive correlations are considered the ones with $r>.7$ (Akoglu, 2018).

\subsection{Reliability Analysis}

Reliability analysis shows that all measures have a high level of internal consistency; thus, we calculated the values for each measure to constitute a single index. Reliability coefficients (Cronbach's Alpha) per index are as follows: Nostalgia, $\alpha=.932$, Inspiration, $\alpha=.926$, Positive emotions, $\alpha=.960$.

\subsection{Normality Testing}

A Shapiro-Wilk test showed a significant departure from normality for most cases: 
the sig. value of the Shapiro-Wilk Test is below than .05. Sig. below .05, means that the data significantly deviate from a normal distribution (see Table 1 below).

\subsection{Kruskal-Wallis Test}

A Kruskal-Wallis $\mathrm{H}$ test showed that there was a statistically significant difference in ideas, $\chi^{2}(2)=23.179, p=.000$ and nostalgia, $\chi^{2}(2)=18.537, p=.000$. No statistically significant difference is observed between the groups in inspiration, $\chi^{2}(2)=6.441, p=.092$ and positive emotions, $\chi^{2}(2)=5.579, p=.139$ (see Table 2).

The mean rank of number of ideas generated was 53.08 for Olfaction group, 79.55 for Olfaction \& memory group, 39.72 for Control group and 69.65 for Memory group. For nostalgia score the mean rank was 54.03 for Olfaction group, 72.08 for Olfaction \& memory group, 41.90 for Control group and 75.62 for Memory group. For inspiration score the mean rank was 50.22 for Olfaction group, 68.87 for Olfaction \& memory group, 55.08 for Control group and 67.79 for Memory group. Finally, for positive emotions score the mean rank was 53.57 for Olfaction group, 70.39 for Olfaction \& memory group, 66.05 for Control group and 53.68 for Memory group (see Table 3).

\subsection{Dunn's Multiple Comparison Test}

A Kruskal-Wallis test provided very strong evidence of a difference $(p<.001)$

Table 1. Shapiro-Wilk test.

\begin{tabular}{|c|c|c|c|c|}
\hline \multicolumn{5}{|c|}{ Tests of Normality ${ }^{*}$} \\
\hline \multirow{2}{*}{\multicolumn{2}{|c|}{ Condition }} & \multicolumn{3}{|c|}{ Shapiro-Wilk } \\
\hline & & Statistic & df & Sig. \\
\hline \multirow{4}{*}{ Nostalgia } & Olfaction & .956 & 30 & .239 \\
\hline & Olfaction \& memory & .898 & 30 & .007 \\
\hline & Control & .938 & 30 & .081 \\
\hline & Memory & .946 & 29 & .142 \\
\hline \multirow{4}{*}{ Inspiration } & Olfaction & .956 & 30 & .237 \\
\hline & Olfaction \& memory & .935 & 30 & .066 \\
\hline & Control & .971 & 30 & .575 \\
\hline & Memory & .945 & 29 & .134 \\
\hline \multirow{4}{*}{ Positive emotions } & Olfaction & .941 & 30 & .096 \\
\hline & Olfaction \& memory & .951 & 30 & .180 \\
\hline & Control & .945 & 30 & .123 \\
\hline & Memory & .944 & 29 & .124 \\
\hline \multirow{4}{*}{ Ideas (fluency index) } & Olfaction & .931 & 30 & .054 \\
\hline & Olfaction \& memory & .935 & 30 & .066 \\
\hline & Control & .940 & 30 & .091 \\
\hline & Memory & .968 & 29 & .506 \\
\hline
\end{tabular}

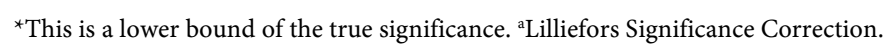


Table 2. Kruskal-Wallis test.

\begin{tabular}{ccccc}
\hline \multicolumn{5}{c}{ Test Statistics, $^{\mathrm{a}, \mathrm{b}}$} \\
\hline & Ideas & Nostalgia & Inspiration & Positive emotions \\
\hline Kruskal-Wallis H & 23.179 & 18.537 & 6.441 & 5.579 \\
df & 3 & 3 & 3 & 3 \\
Asymp. Sig. & .000 & .000 & .092 & .134 \\
\hline
\end{tabular}

${ }^{a}$ Kruskal Wallis Test; ${ }^{\mathrm{b}}$ Grouping Variable: Condition.

Table 3. Mean ranks.

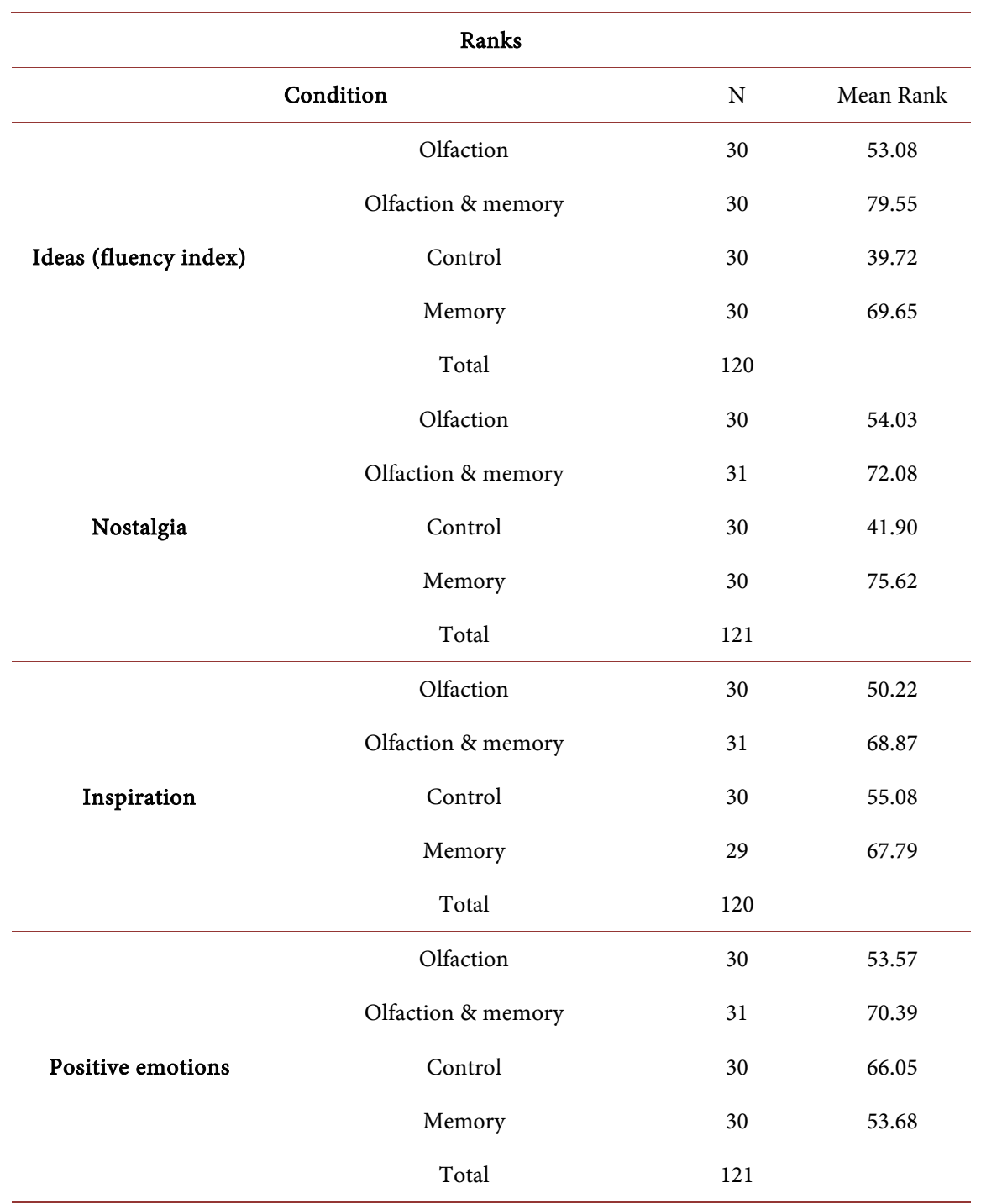

between the mean ranks of at least one pair of groups. Dunn's pairwise tests were carried out for the four pairs of groups. There was very strong evidence ( $p$ $<.001$, adjusted using the Bonferroni correction) of a difference between Memory and Olfaction \& memory groups with Control in nostalgia; the average of nostalgia for Memory group was 4.6, 4.3 for Olfaction \& memory group, 3.7 for 
Olfaction group and 3.2 for Control group (see also Figure 3). The number of ideas generated in the Memory \& Olfaction group is 1236, 1085 in the Memory group, 946 in the Olfaction group and 797 in the Control group (see also Figure 6). Also, significant differences $(p<.001)$ were observed in number of ideas between Olfaction \& memory and Memory groups with Control group and between Olfactory group with Olfaction \& memory group; no sig. differences are observed between Memory and Olfaction groups or between Olfaction and Control group (see Figure 6). There was no evidence of a sig. difference between the groups in inspiration and positive emotions (see Figure 4 \& Figure 5) (Field, 2013).

\subsection{Correlation Analysis (Spearman Correlation)}

A Spearman's rank-order correlation was run to determine the relationship between nostalgia, inspiration and positive emotion marks. There was a moderate, positive and statistically significant correlation between nostalgia and inspiration $\left(r_{s}=.640\right)$, nostalgia and positive emotions $\left(r_{s}=.547\right)$ and between inspiration and positive emotions $\left(r_{s}=.532\right)$ (Akoglu, 2018) (see Table 4).

\subsection{Originality Scores}

Originality scores (original responses unique in each group for each exercise) were calculated to constitute a single originality score per group. Similar pattern is observed in the group ranking based on originality (see Figure 7) as in fluency (see Figure 6). Olfaction \& memory group seems to have generated the most original ideas in total followed by the Memory group (Figure 7).

\section{Discussion}

The results of the study provide empirical support for the fact that nostalgia

Table 4. Spearman correlation-Memory \& olfaction group.

\begin{tabular}{|c|c|c|c|c|c|}
\hline \multicolumn{6}{|c|}{ Correlations } \\
\hline & & & Nostalgia & Inspiration & Positive emotions \\
\hline & & Correlation Coefficient & 1.000 & $.640^{* *}$ & $.547^{* *}$ \\
\hline & Nostalgia & Sig. (2-tailed) & & .000 & .002 \\
\hline & & $\mathrm{N}$ & 30 & 30 & 30 \\
\hline & & Correlation Coefficient & $.640^{* *}$ & 1.000 & $.532^{* *}$ \\
\hline \multirow[t]{5}{*}{$\begin{array}{l}\text { Spearman's } \\
\text { rho }\end{array}$} & Inspiration & Sig. (2-tailed) & .000 & & .002 \\
\hline & & $\mathrm{N}$ & 30 & 30 & 30 \\
\hline & & Correlation Coefficient & $.547^{* *}$ & $.532^{* *}$ & 1.000 \\
\hline & $\begin{array}{l}\text { Positive } \\
\text { emotions }\end{array}$ & Sig. (2-tailed) & .002 & .002 & \\
\hline & & $\mathrm{N}$ & 30 & 30 & 30 \\
\hline
\end{tabular}

${ }^{* *}$ Correlation is significant at the .01 level (2-tailed). 


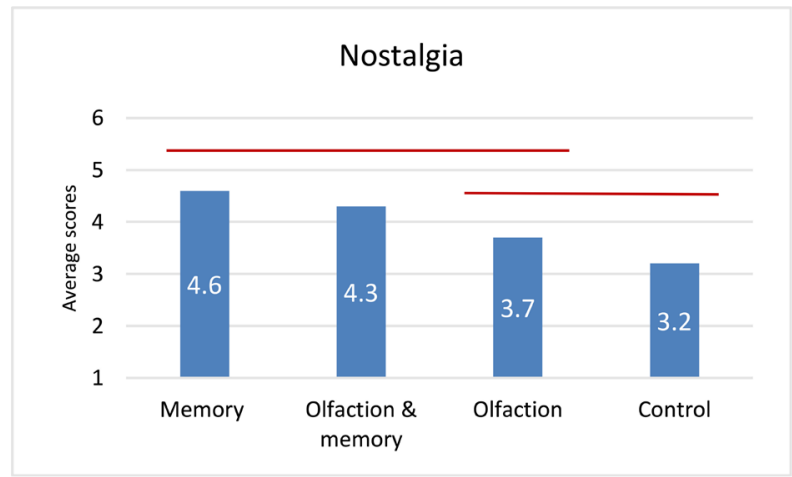

Figure 3. Nostalgia. no sig. difference (95\%cl).

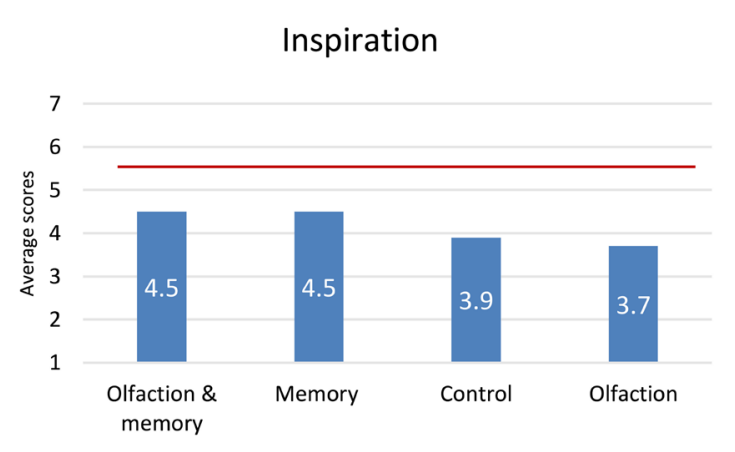

Figure 4. Inspiration. no sig. difference $(95 \% \mathrm{cl})$.

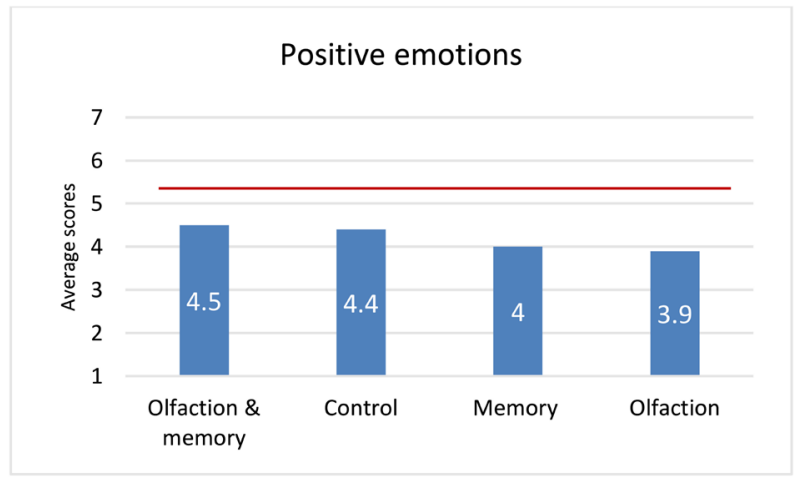

Figure 5. Positive emotions. no sig. difference (95\%cl).

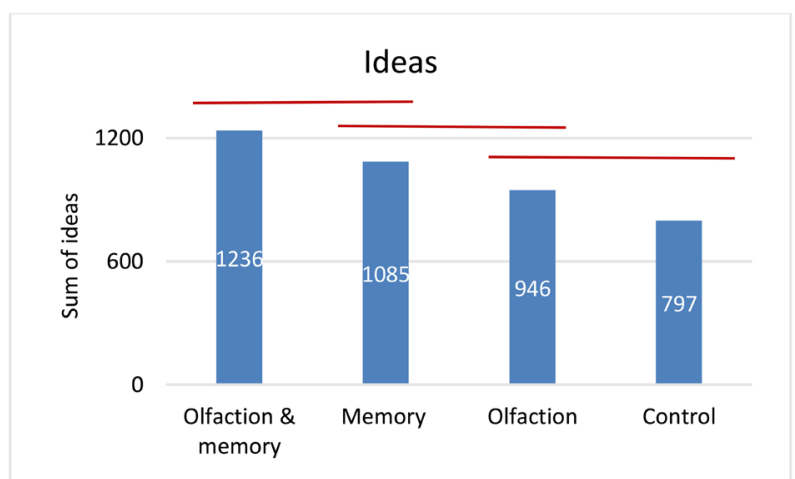

Figure 6. Ideas (fluency index). no sig. difference $(95 \% \mathrm{cl})$. 


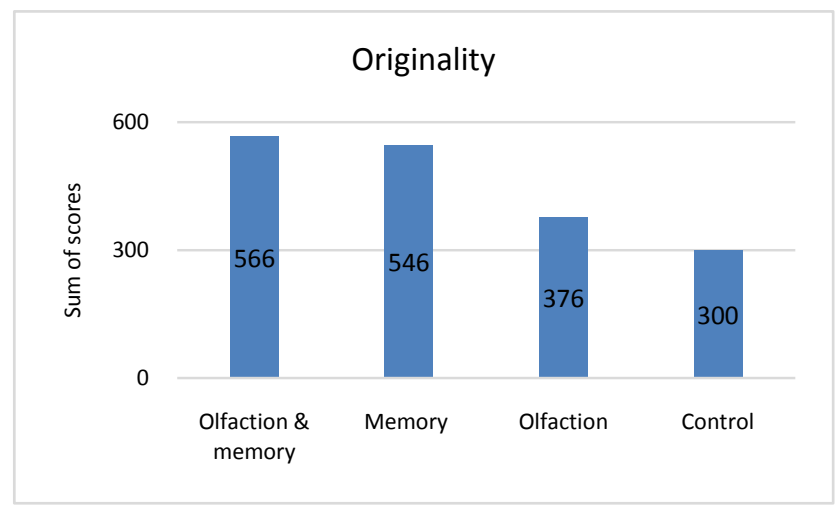

Figure 7. Originality.

increases creativity—fluency and originality (Ye, Ngan, \& Hui, 2013). Olfaction \& memory and memory groups generated a significantly larger quantity of ideas than the control. Also, the study shows that olfactory nostalgia per se does not significantly impact creativity and that it needs to be combined with the reflection of nostalgic experiences to effectively function. It seems that time for reflection is very critical to for the mind to navigate in the past and retrieve memories that will be used for creativity (Routledge, Arndt, Sedikides, \& Wildschut, 2008). Olfactory scents seem to be serving as the sensory triggers of the process for a stronger reflection and memory recall (Chu \& Downes, 2002, 2000).

Also, despite that olfactory \& memory and memory groups had the highest scores in inspiration no significant differences are observed between the study groups. In addition, all groups are at parity in positive emotions. These findings could be attributed to various factors (i.e., age, novices vs experts etc.). For example, research has shown that younger people have better short-term and getto-the-point-quickly memory, whereas older adults have had a greater variety of experiences for which they can feel more easily and strongly sentimental and nostalgic (Salthouse, 2010). Furthermore, an older adult could be more easily distracted and more prone to daydreaming (Gergov \& Stoyanova, 2013; Salthouse, 2010). This means that the impact of nostalgia could be stronger in older adult groups rather than young adults. Another example is the findings concerning the difference between experts vs novices. Research has shown that experts tend to allocate more of their time to the early or preparatory stages of problem solving, whereas novices tend to spend relatively more of their time in the later stages (Shuell, 1986). The current study was conducted with novices, bachelor psychology students, and possibly the impact of nostalgia on inspiration could have been higher in older groups.

Finally, the study confirms the psychological functions and particularly the positive impact of nostalgia (Chrea et al., 2007). Specifically, the study shows positive and statistically significant correlation between nostalgia and inspiration and between inspiration and positive emotions (see Table 4) (Reid et al., 2015; Chu \& Downes, 2002). 


\subsection{Limitations and Future Directions}

The results of this study should be considered directional since there are various factors that could affect the results and, thus, should be taken into consideration for future research. For example, the vast majority of the sample was women $\left(M_{\text {age }}\right.$ = 21) bachelor students of psychology. Both the age (Gergov \& Stoyanova, 2013; Salthouse, 2010) and level of expertise (Shuell, 1986) may have affected nostalgia's impact.

Another important factor to consider is the scent that was used to trigger nostalgia. Bubblegum is a childhood scent that evokes nostalgia from the category of sweets and treats (Petratou et al., 2020). It would be interesting to explore olfactory \& memory nostalgia effect on creativity and the mediating psychological functions with a broader variety of scent categories factoring in gender, age or other individual differences (i.e., personality traits, place of origin).

\subsection{Practical Implications}

Overall, experimental evidence affirmed the causal impact of nostalgia (memory or olfaction \& memory) on creativity. Also, the results showed that positive affect and inspiration mediate the effect of nostalgia on creativity (Reid et al., 2015; van Tilburg et al., 2015; Chu \& Downes, 2002). Further investigation of the causal relation between nostalgia and creativity could be further explored to confirm these findings considering also factors that could affect the output and/ or individual differences. For example, nostalgia has a beneficial influence on creativity (through positive affect and inspiration). However, nostalgia may not be equally beneficial to all. Research shows that individuals who worry on a regular basis (compared to those who do so rarely) experienced positive affect (an index of hedonic wellbeing) immediately following nostalgia induction but showed symptoms of depressive affect and anxiety soon thereafter (Verplanken, 2012).

Furthermore, the current findings have interventional potential. For example, nostalgia could be induced in various contexts/settings (e.g., schools, art schools, businesses, homes) to enhance people's creativity skills and leverage their creative thinking capability.

Nostalgia-based (memory \& olfaction) interventions could be also useful to mental health professionals to trigger nostalgia during the therapeutic process accessing difficult memories and/or for mind relaxation activities (Torre, 2008).

The current findings also suggest that nostalgia (memory \& olfaction) has potential use in marketing (nostalgia marketing), the consumer psychology field and branding. For example, research has demonstrated strong evidence of sweet nostalgic brand relationship with culture giving rise to "traditional purchase", evoking authenticity and myths, being associated with symbolic icons and attracting communities of fans (Kessous, 2015).

\section{Conflicts of Interest}

The authors declare no conflicts of interest regarding the publication of this paper. 


\section{References}

Akoglu, H. (2018). User's Guide to Correlation Coefficients. Turkish Journal of Emergency Medicine, 18, 91-93. https://doi.org/10.1016/j.tjem.2018.08.001

Arden, R., Chavez, R. S., Grazioplene, R., \& Jung, R. E. (2010). Neuroimaging Creativity: A Psychometric View. Behavioural Brain Research, 214, 143-156. https://doi.org/10.1016/j.bbr.2010.05.015

Baas, M., De Dreu, C. K. W., \& Nijstad, B. (2008). A Meta-Analysis of 25 Years of MoodCreativity Research: Hedonic Tone, Activation, or Regulatory Focus? Psychological Bulletin, 134, 779-806. https://doi.org/10.1037/a0012815

Bae, C. L., \& Therriault, D. J. (2013). The Cognitive Underpinnings of Creative Thought: A Latent Variable Analysis Exploring the Roles of Intelligence and Working Memory in Three Creative Thinking Processes. Intelligence, 41, 306-320. https://doi.org/10.1016/j.intell.2013.04.008

Barrett, F. S., Grimm, K. J., Robins, R. W., Wildschut, T., Sedikides, C., \& Janata, P. (2010). Music-Evoked Nostalgia: Affect, Memory, and Personality. Emotion, 10, 390-403. https://doi.org/10.1037/a0019006

Batey, M., \& Furnham, A. (2006). Creativity, Intelligence, and Personality: A Critical Review of the Scattered Literature. Genetic, Social, and General Psychology Monographs, 132, 355-429. https://doi.org/10.3200/MONO.132.4.355-430

Benedek, M., Konen, T., \& Neubauer, A. C. (2012). Associative Abilities Underlying Creativity. Psychology of Aesthetics, Creativity, and the Arts, 6, 273-281. https://doi.org/10.1037/a0027059

Brophy, D. R. (2000). Comparing the Attributes, Activities, and Performance of Divergent, Convergent, and Combination Thinkers. Creativity Research Journal, 13, 439455. https://doi.org/10.1207/S15326934CRJ1334 20

Cheung, W. Y., Wildschut, T., Sedikides, C., Hepper, E. G., Arndt, J., \& Vingerhoets, A. J. J. M. (2013). Back to the Future: Nostalgia Increases Optimism. Personality and Social Psychology Bulletin, 39, 1484-1496. https://doi.org/10.1177/0146167213499187

Cheung, W., Sedikides, C., \& Wildschut, T. (2017). Nostalgia Proneness and Reduced Prejudice. Personality and Individual Differences, 109, 89-97.

https://doi.org/10.1016/j.paid.2016.12.045

Cho, S.-H., Nijenhuis, J.-T., Vianen, A. E. M., Kim, H.-B., \& Lee, K.-H. (2010). The Relationships between Diverse Components of Intelligence and Creativity. Second Quarter, 44, 125-137. https://doi.org/10.1002/j.2162-6057.2010.tb01329.x

Chrea, C., Delplanque, S., Grandjean, D., Cayeux, I., Le Calvé, B., Margot, C., Velazco, M. I., Sander, D., \& Scherer, R. K. (2007). The Emotional Power of Odors: Identifying the Dimensions Referring to Feelings Produced by Odors. SPISE, 43-49.

Chu, S., \& Downes, J. J. (2000). Odor-Evoked Autobiographical Memories: Psychological Investigations of Proustian Phenomena. Chemical Senses, 25, 111-116.

https://doi.org/10.1093/chemse/25.1.111

Chu, S., \& Downes, J. J. (2002). Proust Nose Best: Odors Are Better Cues of Autobiographical Memory. Memory and Cognition, 30, 511-518. https://doi.org/10.3758/BF03194952

Cohen, J., Cohen, P., West, S. G., \& Aiken, L. S. (2002). Applied Multiple Regression/ Correlation Analysis for the Behavioral Sciences (2nd ed.). Mahwah, NJ: Lawrence Erlbaum Associates Publishers.

Corder, G. W., \& Foreman, D. I. (2009). Nonparametric Statistics for Non-Statisticians. Hoboken, NJ: John Wiley \& Sons. https://doi.org/10.1002/9781118165881

Cropley, A., \& Maslany, G. (1969). Reliability and Factorial Validity of the Wallach-Kogan 
Creativity Tests. British Journal of Psychology, 60, 395-398.

https://doi.org/10.1111/j.2044-8295.1969.tb01213.x

Eysenck, H. J. (1995). Creativity as a Product of Intelligence and Personality. In D. H. Saklofske, \& M. Zeidner (Eds.), International Handbook of Personality and Intelligence (pp. 231-247). New York, London: Plenum Press.

https://doi.org/10.1007/978-1-4757-5571-8 12

Field, A. (2013). Discovering Statistics Using SPSS: (And Sex and Drugs and Rock " $n$ " Roll) (4th ed.). London: SAGE.

Finke, R. A., Ward, T. B., \& Smith, S. M. (1992). Creative Cognition: Theory, Research, and Applications. Cambridge, MA: MIT Press.

Gergov, T., \& Stoyanova, S. (2013). Sentimentality and Nostalgia in Elderly People: Psychometric Properties of a New Questionnaire. Psychological Thought, 6, 358-375. https://doi.org/10.5964/psyct.v6i2.90

Goff, K., \& Torrance, E. P. (2002). Abbreviated Torrance Test for Adults Manual. Bensenville, IL: Scholastic Testing Service.

Griffith, D. R., \& Clark, P. M. (1981). Motivation, Intelligence, and Creative Behavior in Elementary School Children of Low-Creative Ability. The Journal of Experimental Education, 49, 229-234. https://doi.org/10.1080/00220973.1981.11011789

Guilford, J. P. (1967). The Nature of Human Intelligence. New York, NY: McGraw-Hill.

Guilford, J. P., Merrifield, P. R., \& Wilson, R. C. (1958). Unusual Uses Test. Orange, CA: Sheridan Psychological Services.

Hepper, E. G., Ritchie, T. D., Sedikides, C., \& Wildschut, T. (2012). Odyssey's End: Lay Conceptions of Nostalgia Reflect Its Original Homeric Meaning. Emotion, 12, 102-119. https://doi.org/10.1037/a0025167

Kazelskis, R., Jenkins, J., Lingle, R., \& Kazekskis, R. (1972). Two Alternative Definitions of Creativity and Their Relationships with Intelligence. The Journal of Experimental Education, 41, 58-62. http://www.jstor.org/stable/20157326 https://doi.org/10.1080/00220973.1972.11011373

Kessous, A. (2015). Nostalgia and Brands: A Sweet Rather than a Bitter Cultural Evocation of the Past. Journal of Marketing Management, 31, 1899-1923. https://doi.org/10.1080/0267257X.2015.1088889

Martindale, C. (1999). Biological Bases of Creativity. In R. J. Sternberg (Ed.), Handbook of Creativity (pp. 137-152). New York: Cambridge University Press. https://doi.org/10.1017/CBO9780511807916.009

Nusbaum, E. C., \& Silvia, P. J. (2011). Are Intelligence and Creativity Really So Different?: Fluid Intelligence, Executive Processes, and Strategy Use in Divergent Thinking. Intelligence, 39, 36-45. https://doi.org/10.1016/j.intell.2010.11.002

Petratou, E., Paradisi, N., Diamantis, O., \& Stalikas, A. (2020). Psychological Implications of nostalgic Scents of Childhood. Psychology, 11, 2066-2080.

https://doi.org/10.4236/psych.2020.1112129

Petratou, E., Perzikianidis, C., \& Stalikas, A. (2019). The Greek Version of the Southampton Nostalgia Scale: Psychometric Properties in Young Adults and Associations with Life Satisfaction, Positive and Negative Emotions, Time Perspective and Wellbeing. Journal of Psychological and Behavioral Sciences, 13.

Plucker, J. A., \& Renzulli, J. S. (1999). Psychometric Approaches to the Study of Human Creativity. In R. J. Sternberg (Ed.), Handbook of Creativity (pp. 35-61). New York: Cambridge University Press. https://doi.org/10.1017/CBO9780511807916.005

Ramaekers, M. G., Boesveldt, S., Lakemond, C. M. M., van Boekel, M. A. J. S., \& Luning, 
P. A. (2014). Odors: Appetizing or Satiating? Development of Appetite during Odor Exposure over Time. International Journal of Obesity, 38, 650-656. https://doi.org/10.1038/ijo.2013.143

Reid, C. A., Green, J. D., Wildschut, T., \& Sedikides, C. (2015). Scent-Evoked Nostalgia. Memory, 23, 157-166. https://doi.org/10.1080/09658211.2013.876048

Routledge, C., Arndt, J., Sedikides, C., \& Wildschut, T. (2008). A Blast from the Past: The Terror Management Function of Nostalgia. Journal of Experimental Social Psychology, 44, 132-140. https://doi.org/10.1016/j.jesp.2006.11.001

Routledge, C., Arndt, J., Wildschut, T., Sedikides, C., Hart, C. M., Juhl, J. et al. (2011). The Past Makes the Present Meaningful: Nostalgia as an Existential Resource. Journal of Personality and Social Psychology, 101, 638-652. https://doi.org/10.1037/a0024292

Royet, J.-P., Zald, D., Versace, R., Costes, N., Lavenne,F., Koenig, O., \& Gervais, R. (2000). Emotional Responses to Pleasant and Unpleasant Olfactory, Visual, and Auditory Stimuli: A Positron Emission Tomography Study. The Journal of Neuroscience, 20, 7752-7759. https://doi.org/10.1523/JNEUROSCI.20-20-07752.2000

Runco, M. A. (2014). Creativity: Theories and Themes: Research, Development, and Practice. Amsterdam, The Netherlands: Elsevier.

Runco, M. A., \& Jaeger, G. J. (2012). The Standard Definition of Creativity. Creativity Research Journal, 24, 92-96. https://doi.org/10.1080/10400419.2012.650092

Şahin, F., \& Lee, J. (2016). General Intelligence, Emotional Intelligence and Academic Knowledge as Predictors of Creativity Domains: A Study of Gifted Students. Cogent Education, 3, Article No. 1218315. https://doi.org/10.1080/2331186X.2016.1218315

Salthouse, T. (2010). Major Issues in Cognitive Aging. Oxford: Oxford University Press. https://doi.org/10.1093/acprof:oso/9780195372151.001.0001

Sedikides, C., Wildschut, T., Arndt, J., \& Routledge, C. (2006). Affect and the Self. In J. P. Forgas (Ed.), Affect in Social Thinking and Behavior: Frontiers in Social Psychology (pp. 197-215). New York, NY: Psychology Press.

Sedikides, C., Wildschut, T., Arndt, J., \& Routledge, C. (2008). Nostalgia Past, Present, Future. Current Directions in Psychological Science, 17, 304-307.

https://doi.org/10.1111/j.1467-8721.2008.00595.x

Shuell, T. J. (1986). Individual Differences: Changing Conceptions in Research and Practice. American Journal of Education, 94, 356-377. https://www.jstor.org/stable/1085157 https://doi.org/10.1086/443854

Silvia, P. J. (2008). Creativity and Intelligence Revisited: A Reanalysis of Wallach and Kogan (1965). Creativity Research Journal, 20, 34-39. http://library.uncg.edu/ https://doi.org/10.1080/10400410701841807

Snyder, A., Mitchell, J., Bossomaier, T., \& Pallier, G. (2004). The Creativity Quotient: An Objective Scoring of Ideational Fluency. Creativity Research Journal, 16, 415-419. https://doi.org/10.1080/10400410409534552

Soudry, Y., Lemogne, C., Malinvaud, D., Laccourreye, O., Consoli, S.-M., \& Bonfils, P. (2011). Olfactory System and Emotion: Common Substrates. European Annals of Otorhinolaryngology, Head and Neck Diseases, 128, 18-23.

https://doi.org/10.1016/j.anorl.2010.09.007

Thode, H. J. (2002). Testing for Normality. Boca Raton, FL: CRC Press. https://doi.org/10.1201/9780203910894

Thrash, T. M., \& Elliot, A. J. (2003). Inspiration as a Psychological Construct. Journal of Personality and Social Psychology, 84, 871-889.

https://doi.org/10.1037/0022-3514.84.4.871 
Torre, M. A. (2008). Integrated Perspectives: Aromatherapy and the Use of Scents in Psychotherapy. Perspectives in Psychiatric Care, 39, 35-37.

https://doi.org/10.1111/j.1744-6163.2003.tb00672.x

van Tilburg, W. A. P., Sedikides, C., \& Wildschut, T. (2015). The Mnemonic Muse: Nostalgia Fosters Creativity through Openness to Experience. Journal of Experimental Social Psychology, 59, 1-7. https://doi.org/10.1016/j.jesp.2015.02.002

Verplanken, B. (2012). When Bittersweet Turns Sour: Adverse Effects of Nostalgia on Habitual Worries. European Journal of Social Psychology, 42, 285-289. https://doi.org/10.1002/ejsp.1852

Vulpe, A., \& Dafinoiu, I. (2011). Positive Emotions' Influence on Attitude toward Change, Creative Thinking, and Their Relationship with Irrational Thinking in Romanian Adolescents. Procedia-Social and Behavioral Sciences, 30, 1935-1941.

https://doi.org/10.1016/j.sbspro.2011.10.376

Wallach, M., \& Kogan, N. (1965a). Modes of Thinking in Young Children. New York: Holt, Rinehart, \& Winston.

Wallach, M., \& Kogan, N. (1965b). A New Look at the Creativity-Intelligence Distinction. Journal of Personality, 33, 348-369. https://doi.org/10.1111/j.1467-6494.1965.tb01391.x

Wildschut, T., Sedikides, C., Arndt, J., \& Routledge, C. (2006). Nostalgia: Content, Triggers, Functions. Journal of Personality and Social Psychology, 91, 975-993. https://doi.org/10.1037/0022-3514.91.5.975

Willander, J., \& Larsson, M. (2006). Smell Your Way Back to Childhood: Autobiographical Odor Memory. Psychonomic Bulletin \& Review, 13, 240-244.

https://doi.org/10.3758/BF03193837

Ye, S., Ngan, R. Y. L. \& Hui, A. N. N. (2013). The State, Not the Trait, of Nostalgia Increases Creativity. Creativity Research Journal, 25, 317-323. https://doi.org/10.1080/10400419.2013.813797

Zmigrod, S., Colzato, L. S., \& Hommel, B. (2015). Stimulating Creativity: Modulation of Convergent and Divergent Thinking by Transcranial Direct Stimulation (tDCS). Creativity Research Journal, 27, 353-360. https://doi.org/10.1080/10400419.2015.1087280 